\title{
Use of Audiovisual Texts in University Education Process
}

\author{
Evgeniy P. Aleksandrov \\ Taganrog Institute of Management and Economy, Russia \\ *Corresponding Author: ealeksandrov@yandex.ru
}

Copyright (C) 2014 Horizon Research Publishing All rights reserved.

\begin{abstract}
Audio-visual learning technologies offer great opportunities in the development of students' analytical and projective abilities. These technologies can be used in classroom activities and for homework. This article discusses the features of audiovisual media texts use in a series of social sciences and humanities in the University curriculum.
\end{abstract}

Keywords Media Text, Cognitive Scheme, Didactic Adaptation of Media Texts

\section{Introduction}

Vocational training of future professionals cannot be described in a textbook as it shows up in non-standard situations. Efficiency of professional decisions is closely related to the depth of the learners' obvious and hidden motives of behavior understanding. Besides, the expert has to expect consequences (including ethical) of decisions made. But even standard situations never repeat (as it is impossible to enter the same river twice). Therefore the professional has to be ready to extrapolate semantic context from one situation into another.

Communication and life experiences, knowledge and images are converted into cognitive schemes, which in turn become the basis for reflection and re-evaluation of incoming information, help select behavior patterns. Professionals attribute the situation observed and correlate with cognitive schemas stored in their memory. In a single unique event they recognize the features of a well-known ones, this facts allows them to make the right professional decisions [1].

Schemes main function is a causal interpretation of problem situations as well as the sequence of events and actions, also feelings of people involved. On this basis prognostic analysis capabilities are discovered as cognitive schemes provide the ability to go beyond the directly observed, to allow drawing conclusions about the event potential developments. Therefore, cognitive schemes can be understood as the active component of the psyche, in the process of being formed on the dialogic nature of cognitive activity [2], [3].
Cognitive schemes are standardized as they do not take into account all the details of the situations, have a certain "degree of freedom" and variability. A professional expertise is determined by the fund of relevant cognitive schemes which may be used in the analysis of the situation. Therefore, it is claimed that in the learning process future professionals create, fix, transform, combine, and complement cognitive schemes important from a professional point of view.

Application of media texts in educational process (provided their didactic adaptation) can become a powerful factor in the professional development of students, as it expands the boundaries of their analytical experience. With this purpose in mind adapted audiovisual texts (for example, fragments of films and documentaries, TV programs) can be used in a didactic manner.

\section{Methods}

In the process of studying the humanities students can generate the following cognitive schemes:

a. knowledge of the values, characteristics, conditions, standards, models, methods and technologies, activities of a social worker; psychological and social differences of people interacting in a professional environment; main reasons for social and psychological tension and conflicts and deviant behavior;

b. operational scheme of liberal education useful for their professional practice. For example:

- diagnostic schemes on the basis of which information (including diagrams of sociological and psychological diagnostics) is collected, classified and interpreted;

- ad hoc schemes, through which students develop skills to transfer peculiarities of observed situations into words and vice versa;

- occupational schemes of understandability including the schemes of transmission of values to others (differing in social and psychological characteristics), value grounds of professional activity;

- schemes of the intentions understanding and interpretation to other members of interaction and 
providing adequate responses to them $[5,6,7]$;

- schemes of understanding and interpreting the intentions transfer in the course of interaction of other participants of the learning process and adequate response to them;

- schemes of adequate responses to the dynamics (changes) of the situation;

- schemes enhance the institutional and extra-institutional resources (informational, legal, economic, psychological, educational, etc.) available to the specialist area of influence;

- patterns of communication and interaction with others. Obviously, the choice of students' behavior is associated with the ability to see themselves and their actions in the light of the other people's perception. Note that the image in the minds of others may be distorted or does not coincide with the self-esteem. Ignoring this fact often negatively affects the understanding and effectiveness of communication;

-schemes validation of incoming information and also information pressure confrontation in the cases where the information affects the interaction between participants and the very situation of interaction;

- schemes of future professionals self-learning and self-tuning;

- schemes of information protection from unauthorized access in circumstances where it can negatively affect the people vital activity (for example, various forms of the youth "philosophical intoxication" in violation of the socio-cultural link between generations and the natural process of socialization).

\section{Didactic Adaptation of Media Texts}

Audiovisual and media texts are used: a) in the theoretical part of the course (primarily as illustrations of basic scientific principles), b) in class (as a teaching material for creative analysis and as business games and creative activities starting point), and c) in homework (for analytical reports and creative activities), d) in extracurricular group discussions.

Initially, most of audiovisual materials are not intended for didactic purposes. They acquire didactic value only as a result of their inclusion in the semantic context of educational process. Therefore, didactic adaptation of the texts is necessary as the following:

1. Selection, fragmentation, methods of presentation and systematization of audiovisual materials for analyzing during lectures and seminars, for analytical experience in homework and in extracurricular group forms of discussions and debates, for creative activities and benchmark analysis is determined by the courses curriculum and the type of class activities.

2. Audio-visual materials are generally presented in fragments (7-10 minutes); the watching stimulates the development of students' abilities to reconstruct a scheme of some private determinants causal relations. The complexity of this reconstruction is mediated by the following:

- the problem situation, the conflict generated not so much by the circumstances in which a person was, as his her relationship with the outside reality. Interpretation of the characters behavior, prediction of events, and analysis of the ways of reducing tension based on the idea of the person and the situation as a whole system. The system, as it is known, tends to stability. Attempts to influence any aspect of the system will inevitably encounter resistance of the system. The change of the system components is possible only if the restructuring of the entire system occurs and vice versa;

- any conflict situation is often the result of long lasting (often latent) processes. Whatever has been accumulated for some time requires long time and a lot of effort to be corrected. That is why the analyzed problem can not be solved by any single action, and requires a combination of multi-way actions;

- causes of conflict situations are very diverse. Sometimes they can be observed, but sometimes they are "hidden" deep in the personality. In this case, the reasons are difficult to analyze. Character close observation allows determining and interpreting the indicators of impending conflict. In this case, a professional can act in advance and reduce tension of the events. Such indicators in media texts may be, for example;

a. the concepts expressed through the separate words, replicas, logic statements, meanings and relationships, plans, expectations, fears, etc.;

b. objects (weapons, household goods, machinery and equipment, clothing and others);

c. emotional experiences and feelings of different intensity;

d. characters and their social and psychological features;

e. animals (whose aggressiveness is a natural part of their behavior or aggression as a means of defense);

f. evidence of socio-cultural reality, that are somehow discussed or referred to in the audio-visual or media texts or on the background of which the action is developed;

g. situations examined in the context of human relations, the relations of individuals and social groups with the socio-cultural environment;

h. actions undertaken by individual characters or groups, including those that can cause aggressive reactions, and the others;

- experience of conflict interactions stimulated by the 
fact that the characters are expecting a certain reaction from the others. Such a social background can act as a factor of support and approval, a factor of strengthening impact factor of consolidation and facilitation;

- charismatic characters behavior that students can identify themselves with. It often makes sense when only the external behavior patterns (e.g., violence) are imitated. The repeated success of a certain behavior pattern stimulates the situation aimed at priority application (regardless of whether it features a real situation).

\section{Criteria for the Audiovisual Texts Selection}

When selecting audiovisual didactic texts for the training purposes a teacher should be guided by the following:

a. only publicly acknowledged high artistic audio-visual texts should be used in the learning process. In this case, the screen event may be perceived by students as a fact of their lives (presence effect). At the same time, there should be some perception "detachment", as the strong emotional involvement limits the professional and analytical activity of students. The scenes of conflict are not of any interest in the educational process. Specifically selected audio-visual texts should be adopted for psychological, cultural and social interpretations;

b. fragmentation of the media text should not lead to irreversible loss of socio-cultural and artistic meaning, fragments should have logical connection, and relative completeness;

c. content fragments should convey not only the individual motives and characters activity meanings, but to some extent reflect the socio-cultural features of the social groups in which these characters belong;

d. situations are valuable for the analysis where a character in a process of choosing behavioral patterns is going through the struggle of motives, experiencing internal and external resistance thus overcoming the difficulties and progressing along;

e. fragments must provide opportunities for interpretation variants, in which creative and socio-cultural potential of identity of the interpreter is being revealed;

f. fragments should be able to extend the time frame of the episode (in the retrospective and prospective aspects) connected with the process of becoming a better person, forecasting future events;

g. appropriate use for educational purposes of fragments containing deep conflict of values, withstanding. The conflict might not be in the form of actual confrontation, but the analysis of characters experiences and actions through the prism of universal moral laws is of great importance; h. class presentation is only a starting point for reflective reasoning on the problem.

Each audio-visual text should be provided with the didactic supporting materials: questions, tasks, themes for creative work, bibliographic references, literary sources, etc. Part of the questions and tasks should appeal to students' life experiences and their socio-cultural awareness.

It is necessary to pay attention to the opportunities of technology application as follows:

- Freeze - on-screen action is interrupted by the teacher to analyze the situation, to predict future events. For example, students are encouraged:

a. to give social and psychological characteristic of the participants of the conflict situation;

b. to characterize the observed "indicators" of the internal state of the characters predicting their conflict interaction, such as vocabulary and style, exstra- and paralinguistic features of speech (tempo, tone and pitch, volume, intermittency, intonation, distribution in the articulation of vowels and consonants, interjections and exclamations and others), facial expressions, gestures and other;

c. to describe the development of the conflict, to restore the previous events, personal development conditions, psychological experiences, to explain the stages of the conflict interaction;

d. to predict the development of events, characters behavior;

e. to analyze the main mistakes made by the participants of conflict interaction (observed in the fragment or being "behind the scenes"), the factors that determined the parties' choice of aggressive reactions, or to describe a different scenario, if these mistakes would not have been made;

f. to imagine themselves as one of the parties of the conflict, to compare their own behavior with the reactions of a media character. This may be considered as examples of conflict activity and examples of non-participation in the conflict. In this case, the participants choose to keep moral positions of the interacting parties of the original media text;

g. to imagine themselves in the role of an onlooker not directly involved in the conflict, but having the opportunity to observe and influence its course;

h. to justify their actions as a leader in situations described by media text. In this situation there are opportunities for "a game gap" - in certain situations time is not limited, and in others precise timing is necessary.

i. Then watching the fragment can be extended, and the conflict development is re-evaluated according to analysis and forecasting results;

j. to retrospectively return to the previously viewed episode to analyze it from a different angle of view, in the light of new arguments or details of the known circumstances to clarify the motives of participants. On this basis the actions are aimed at correcting the 
situation, neutralizing or mitigating the causes of the conflict, harmonization of the situation of social interaction;

k. to change the speed of the track (most often slowing it down). Thank to this students can correctly perceive the precise details of the plot and the characters reactions to the conflict;

1. to re-assemble the episodes in order to reconstruct the sequence of events, to compare different plot variations etc. In particular, by re-assembling the episodes a kind of "multimedia crossword puzzles" can be created. In order to meet the challenge students are suggested to solve the puzzle and to compose a logically consistent story as a result.

\section{Conclusion}

As experience shows, the analysis of audiovisual and media texts causes a classroom discussion comparing the views, positions, proposals, thus opening variant and invariant components of the problem. Discussions allow students to gain experience of reflection in professional interactions, the experience of public argumentation of their own point of view, the experience of understanding the arguments of their partners and tolerance for the views of others, the experience of internalization of a dialogue, experience of group interaction (collaboration, cooperation, competition) to find the optimal problem solutions, etc.

It is known that reasoning is the heart of all intellectual activities. In addition, it should be borne in mind that in any professional practice, we can talk about the dialogic truth, about the additional and complementary forms of speculation and logic [8].

Publicly made analysis is becoming a kind of professional thinking school, enabling students to overcome superficial emotional, chaotic approach to the phenomena of professional reality. Here, students form cognitive schemes, algorithms of analytical activity aimed at the solution of professional problems. In spite of being more sophisticated and time-consuming than traditional forms of teaching the waste of time this type of pedagogical activity is accompanied with is justified by the results achieved.

Analysis of audiovisual and media texts is available to help actualize the students' socio-cultural experience schemas. This provides theory and practice unanimity, professional roles acquisition, which in turn opens up possibilities for creative comprehension of professional reality.

\section{REFERENCES}

[1] Makarova E. Cognitive aspects of Schema Theory application in educational activity// Taganrog Institute of Management and Economics Bulletin. 1 (17). 2013. - pp. 63-66.

[2] Rumelhart D.E. Schemata: the Building Blocks of Cognition. In: Rand J. Spiro, B.C. Bruce, W.F. Brewer (Eds.), Theoretical Issues in Reading Comprehension. Perspectives from Cognitive Psychology, Linguistics, Artificial Intelligence, and Education. Hillsdale, N.J.: Lawrence Erlbaum Associates Publishers, 1980, p. 33.

[3] Roy G. D’Andrade. Cultural Meaning systems. In: Richard A. Shweder, Robert A. LeVine (eds.) Cultural Theory. Essays on Mind, Self, and Emotion. Cambridge, L., NY., New Rochelle, Melbourne, Sydney: Cambridge University Press, 1984, p. 88.

[4] Ross L., Nisbett R. The Person and the Situation: Perspectives of Social Psychology/ trans. By Rumynsky V., ed. By Emelyanov E. - Moscow: Aspect Press, 1999. - 429 p.

[5] Martinez M.A. An investigation into successful learning measuring the impact of learning orientation. A primary learner-difference variable, on learning. A dissertation submitted to the faculty of Brigham Young University for the degree Doctor of Philosophy, 1997-1999. - 151 p.

[6] Bereiter C., Scardamalia M.. Intentional Learning as a goal of Instruction. - http://ikit.org/fulltext/1989intentional.pdf.

[7] Mehlenbacher B. Intentionality and Other «Nonsignificant» Issues in Learning: Commentary on Margaret Martinez's «Intentional Learning in an Intentional World». http://doi.acm.org/10.1145/330409.330413.

[8] Pilkigton R. Analising Educational Dialogue Interaction: Towards Model that Support Learning// International Journal of Intelligence in Education (2001), 12. - P. 1-17. 